\title{
Assessment of Intention and Practice of VCT and Infant Feeding in The Context of HIVIAIDS among Lactating Mothers in Dilla University Referal Hospital, Southern Ethiopia
}

Kaleab Tesfaye Tegegne (BSCPH, MPH)*

Department of Public Health, Hawassa College Of Health Science, Hawassa, Ethiopia

\section{*Corresponding Author}

Kaleab Tesfaye Tegegne

Article History

Received: 14.11 .2019

Accepted: 21.11 .2019

Published: 30.11 .2019

\begin{abstract}
Background: Mother-to-child transmission of HIV is the most significant route of HIV infection in children and by far the largest source of HIV infection in children below the age of 15 years. Objectives: the aim of this study was to assess current practices and future intention of lactating mothers on VCT and infant feeding in relation to prevention of MTCT of HIV in DURH. Methods: Institutional based cross sectional quantitative survey was conducted from February, 1 to February 102008 E.C using standardized questionnaire, among lactating mothers in DURH selected using probability proportional to size. Non probability conveniences (purposive) sampling technique was used. The data was exported in to SPSS software version 20 and analyzed. Official written letter of cooperation were secured from DURH to the concerned body, and verbal consents of the study participants was obtained. Finally the result was presented by using tables and charts. Result: A total of $271(100 \%)$ mothers participated in the study. The majority of the study participants were in the age group of 25 to $34(61.8 \%)$ years. The majority were married $219(80.8 \%)$, house wives in occupation, $113(41.7 \%)$, and had Grade 7-12 that $69(25.5 \%)$ attended high school education. There was statistically association between knowledge and the respondents' educational status $(p=0.037)$, association between attitude towards VCT and the respondents' educational status $(p=0.010)$, as well as between attitude towards VCT and occupation $(p=0.021)$ and there was statistically association between practice towards VCT and the respondents' religion ( $p=0.019)$, as well as between practice towards VCT and monthly income ( $\mathrm{p}=0.041)$. Conclusion and Recommendation: The findings from this study in relation to prevention of HIV transmission revealed that mothers had good knowledge of HIVIAIDS and on MTCT and PMTCT. The study participants also have good attitude towards VCT which may have a contribution to intention of the mothers to have HIV test. Therefore to increasing utilization of PMTCT, infant feeding and VCT it requires to address reinforce the importance of exclusive breast feeding during antenatal and postnatal follow up, prevention of mother to child transmission of HIV (PMTCT) service shall be accessed to some groups of the community such as housemaid and housewives as much as possible to get information utilize the services, and establish communication/ referral network between health facilities and organizations working on HIVIAIDS.
\end{abstract}

Keywords: Infant feeding, VCT, MTCT, PMT.

\section{INTRODUCTION}

As per 2010 global UNAIDS report, the epidemics burden of HIV on women accounted for $50 \%$ of all PLWHA worldwide, $57 \%$ for sub-Saharan Africa. In Ethiopia out of PLWHA women accounts about $51 \%$. According to sentinel surveillance on pregnant women the prevalence of HIV varied across sites from $0.5 \%$ to $30 \% ; 2.2 \%$ to $30.2 \%$ in urban and $0.5 \%$ to $1.9 \%$ rural as reported in June 2004 [1, 2].

Mother to child transmission (MTCT) of HIV is the most significant route and by far the largest source of HIV infection in children below the age of 15 years. Worldwide 2000 infants are infected each day or almost 720,000 per year. In Ethiopia out of PLWHA 96,000 are children less than 15 years [1-3].

In the absence of any intervention, the risk of a baby acquiring the virus from an infected mother ranges from $15 \%$ to $25 \%$ in industrialized countries, and $25 \%$ to $35 \%$ in developing countries. HIV transmission rate and time of transmission is estimated to be

Copyright @ 2019: This is an open-access article distributed under the terms of the Creative Commons Attribution license which permits unrestricted use, distribution, and reproduction in any medium for non commercial use (NonCommercial, or CC-BY-NC) provided the original author and source are credited. 
$5 \%$ to $10 \%$ during pregnancy, $10 \%$ to $15 \%$ during delivery, and $5 \%$ to $20 \%$ during breast feeding. Overall, without breastfeeding $15 \%$ to $25 \%$, with breast feeding to six months $20 \%$ to $35 \%$ and with breast feeding to 18 to 24 months $30 \%$ to $45 \%$ of transmission rate is estimated [3-7].

Mother to child transmission (MTCT) of the virus can occur in the uterus during pregnancy, in the birth canal during delivery, and after birth through breastfeeding. Breastfeeding confers enormous benefits, such as preventing malnutrition and illness, saving lives and money. Nevertheless, it is also one of the ways in which an HIV positive mother could transmit the virus to her infant [2, 3]. Without intervention, the risk of mother-to-child transmission (MTCT) of HIV is $15-30 \%$ in non breast feeding populations; breastfeeding by an infected mother increases the risk by $5-20 \%$ to a total of $20-45 \%$ [4].

Studies have also shown that MTCT of HIV varies with the duration of breast-feeding and pattern of infant feeding. The MTCT rates by duration of breast feeding vary between, $25-35 \%$ if breast feeding through 6 months and $30-45 \%$ if there is breast feeding through 18-24 months [4]. The rate of transmission by pattern of infant feeding was found to be low in exclusively breast-fed $(19.4 \%)$ than mixed fed infants $(26.1 \%)$ for 3 months [5].

This study intends to assess the intention and practice of VCT and infant feeding in the context of HIV using behavioral models. The result of the study produce information that can be used by program managers and stakeholders in the planning and implementation of interventions for improving activities in the context of prevention of HIV transmission from mother to child (PMTCT) scale up.

\section{SUBJECTS AND METHODS \\ Study Area and Period}

The study was conducted in DURH. DURH was first established as a clinic in 1920 E.C which latter in 1950 E.C upgraded to hospital and named as Leul Mekonen In 1977 E.C. The hospital was upgraded to give service for 250,000 people bring the name Dilla district hospital and called DURH. Currently it provide service for about 2 million catchment population with a total capacity of about 182 beds and it has 113 nurses (19 midwives), 83 general practitioners and 4 seniors(permanent). It provide range of service in outpatient (2576/month), in patient and emergency basis (625/month) in various areas; namely internal medicine, pediatrics, obstetrics and gynecology, surgery, dentistry, ophthalmology and psychiatry.

The study was conducted from February 1 to February 10, 2008 E.C.

\section{Study Design}

Institutional based cross sectional study was conducted to assess intention and practices of VCT and breast feeding.

\section{Study Population}

All lactating mothers having a child/ children younger(less) than one year without considering their HIV status.

\section{Inclusion and Exclusion Criteria Inclusion Criteria}

Mothers, who gave birth in the past 12 months of study period, as reported by the respondents without considering their HIV status, was included in the study from the selected hospital.

\section{Exclusion Criteria} the study.

A mother who did not satisfy the inclusion criteria and who were not willing to give an informed consent was excluded from

\section{Sample Size and Sampling Technique}

Sample size was estimated as 50\% practice rate of VCT among lactating mothers. Five percent marginal error with $95 \%$ confidence of certainty of any outcome was used. Based on this the actual sample size calculated using the formula for single population proportion,

$$
\mathrm{n}=(\mathrm{Z} \text { á/2)2 P (1-P)/d2 }
$$

Where,

$$
\begin{aligned}
& P=\text { the prevalence of practice of HIV testing among lactating mothers }(0.50) \\
& d=\text { marginal error between the sample and the population }(0.05) \\
& Z=\text { Critical value at } 95 \% \text { certainty }(1.96)
\end{aligned}
$$

$$
\mathrm{n}=\frac{(1.96)^{2} \times 0.5(1-0.5)}{(0.05)^{2}}=384
$$


Since the total population is $<10,000$, I used correction formula.

$$
\mathrm{nf}=\mathrm{ni} \underset{(1+\underline{\mathrm{ni} / \mathrm{N})}}{ }=245
$$

The calculated sample size was 245 .Considering 10\% non response rate, the overall sample size was 271 .

Non probability conveniences (purposive) sampling technique was used. Participant was selected by me when i was gone to the institute for data collection.

\section{Data Collection Procedures}

The questionnaires were developed according to theoretical behavioral models; Health belief model (HBM), theory of planned reasoned action (PRA) and PRECEDE-PROCEED model (38).Quantitative data was collected using standardized structured questionnaires [39].

\section{Data Quality Assurance} interviewers.

Quality of data assured through pretesting of the questionnaire on $5 \%$ of population Data was collected by trained

The interviewers conducted the structured interviews under the supervision of the investigator. Every day $5 \%$ of the questionnaire was randomly selected and checked for completeness and consistencies.

Pre coded data was entered, and cleaned in EPI 6 software version. The data was exported in to SPSS software version 20 and analyzed. Frequencies, proportion and summary statistics was used to describe the study population in relation to relevant variables.

\section{Data Processing and Analysis}

The quantitative data was checked, edited, and entered to SPSS software version 20 . The study also employed chi-square analysis models. In order to determine their prediction as well as their determinations for other dependent (out comes) dichotomization was done using their mean after checking their distribution. Those who scores mean and above were considered as having good knowledge or attitude. Finally socio-demographic variables were included to appreciate how each component improved the performance of the model. The result was presented using descriptive statistics using tables, graphs and charts.

\section{Operational Definition}

Behavioral Intention - Readiness or willingness of an individual to perform a certain behavior. Behavioral modeling-An attempt to identify and propose a working set of determinant factors which are thought to be the most important ones in affecting or influencing behaviors.

Exclusive breast feeding - Giving the infant no other food or drink rather than breast milk, not even water, apart from breast milk (Including expressed breast milk), with the exception of drops or syrups consisting of vitamins, mineral supplements or prescribed medicines.

Predominantly breast feeding - Infants who feed on breast milk and other fluids like tea, water and juice but not other milk products.

Mixed feeding- Giving a baby breast milk and milk products such as formula milk and cow milk including solid and semi sold foods.

Replacement feeding- The process of feeding a child who is not receiving breast milk with a diet that provides all the nutrients to the child needs until the child is fully fed on family foods.

Complementary feeding- Giving other foods (called complementary foods) in addition to breast milk.

Good knowledge of HIVIAIDS- those respondents with mean score and above related to questions of mode of transmission of HIV are considered as having good knowledge and scores less than mean are considered as having poor knowledge.

Good knowledge of MTCT of HIV - those respondents with mean score and above to questions on time of transmission of HIV from mother to child are considered as having good knowledge and scores less than mean are considered as having poor knowledge. 
Good knowledge of PMTCT of HIV - those respondents with mean score and above to the questions pertaining to prevention of HIV transmission from mother to child are considered as having good knowledge and scores less than mean are considered as having poor knowledge.

Good attitude towards HIVIAIDS - those respondents with mean score and above to the questions pertaining to attitudes towards HIVIAIDS are considered as having good attitude and scores less than mean are considered as having bad attitude.

Good attitude towards VCT - those respondents with mean score and above to the questions pertaining to attitudes towards VCT are considered as having good attitude and scores less than mean are considered as having bad attitude.

\section{Ethical Considerations}

Official written letter of cooperation was provided by Rift Valley University Hawassa Campus Ethical review board to the concerned body and verbal consents of the study participants were obtained. All the interviews with subjects were made with strict privacy. The right of the respondents to refuse answer for few or all of the questions was respected. During data collection necessary advice was given for mothers practicing suboptimal breast feeding.

\section{RESULTS}

A total of $271(100 \%)$ mothers participated in the study. The majority of the study participants were in the age group of 25 to $34(61.8 \%)$ years. The majority were married $219(80.8 \%)$, house wives in occupation, $113(41.7 \%)$, and had Grade 7-12 that 69 $(25.5 \%)$ attended high school education. In case of religion of mothers, protestant accounts about 125 (46.1\%). Gedeo, Oromo, Amahara, Gurage and sidama ethnic groups constituted 135 (49.8\%), $65(24.0 \%), 43(15.9 \%) 8(3.0 \%)$ and $5(1.8 \%)$ respectively. Majority of the study participants $115(42.4 \%)$ were earn more than 1000 ETB per month Most of the mothers (74.6\%) are mulitpara with and had ANC follow up (79.3\%) during the last pregnancy. Similarly, majority of the mothers in the study (52.8\%) had antenatal visits either in the second or third trimester. The majority (58.2\%) had antenatal follow up more than one times and the majority of the mothers in the study (83.1\%) were deliver at health institution with majority of health professional $(79.0 \%)$ delivery assistance. Table2 depicts the obstetric history of the study participants.

\section{KNOWELEDGE ABOUT HIVIAIDS, MTCT and PMTCT}

A total of three closed ended questions were included to assess the knowledge status of the study population about HIV transmission including MTCT. Out of the total 271 respondents for mode of HIV transmission 226 (82.8 \%) had good knowledge on HIVIAIDS, and the rests 45 (17.2\%) are poor knowledge

\section{Comparison of knowledge about HIVIAIDS, MTCT and PMTCT across independent variables}

Comparing knowledge to different demographic characteristics (age, marital status, educational status............) using the chi-square test indicated that there was statistically association between knowledge and the respondents' educational status $(p=0.037)$. There was no association between HIVIAIDS, MTCT and PMTCT knowledge and the other independent variables

\section{Perception of risk of acquiring HIV, and severity of HIV}

Among 271 respondents $244(90 \%)$ reported they are susceptible to or at risk of acquiring HIV. The reasons for their perceived susceptibility were multiple sexual partner $112(41.3 \%)$, sexual practices without condom $39(14.4 \%)$, and other reasons 93 (34.3) including history of receiving blood transfusion, history of STDs like genital ulcer, used contaminated sharp objects and others.

Those who reported they don't feel susceptible mentioned reasons such as trusting one's own sexual partner 104 (38.1\%), having single sexual partner $99(36.3 \%)$, having no history of

\section{Attitude of Voluntary Counselling and Testing}

A total of three questions were included to assess about attitude of VCT pertaining to discussion about VCT with partner, importance of VCT for pregnant mothers and advantage of having VCT for pregnant mother by Likert's scale. Out of 271 respondents $209(76.3 \%)$ had good attitude and $62(23.7 \%)$ of them had poor attitude towards VCT.

Unsafe injection $21(7.7 \%)$ and using condom during sexual contacts 11(4.0\%). Out of 271 responded for this question, $235(86.1 \%)$ perceived severity of HIV IAIDS from their experiences of illness and suffering of AIDS patients. 
Table-1: Attitude of Voluntary Counselling and Testing D.U.R.H February, 2008 E.C

\begin{tabular}{|c|c|c|c|c|c|c|}
\hline \multirow[t]{2}{*}{ Questions } & \multicolumn{2}{|c|}{$\begin{array}{l}\text { HIV testing is } \\
\text { important for } \\
\text { pregnant mother }\end{array}$} & \multicolumn{2}{|c|}{$\begin{array}{l}\text { Discussing about HIV testing with } \\
\text { husband/partner/boy friend is } \\
\text { important }\end{array}$} & \multicolumn{2}{|c|}{$\begin{array}{l}\text { HIV testing / VCT helps for pregnant mother } \\
\text { to receive medicine to prevent her baby from } \\
\text { HIV infection in case the test is positive }\end{array}$} \\
\hline & Frequency & Percent & Frequency & Percent & Frequency & Percent \\
\hline $\begin{array}{l}\text { Strongly } \\
\text { agree }\end{array}$ & 24 & $8.8 \%$ & 46 & $16.8 \%$ & 43 & $15.7 \%$ \\
\hline Agree & 182 & $65.5 \%$ & 181 & $67.1 \%$ & 189 & $70.1 \%$ \\
\hline Neutral & 42 & $15.3 \%$ & 8 & $3.0 \%$ & 39 & $14.2 \%$ \\
\hline Disagree & 19 & $6.9 \%$ & 36 & $13.1 \%$ & - & - \\
\hline $\begin{array}{l}\text { Strongly } \\
\text { disagree }\end{array}$ & 4 & $1.5 \%$ & - & 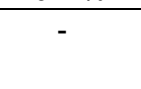 & - & - \\
\hline Total & 271 & $100 \%$ & 271 & $100 \%$ & 271 & $100 \%$ \\
\hline
\end{tabular}

Table-2: Attitude towards VCT D.U.R.H February, 2008 E.C

\begin{tabular}{|c|c|c|}
\hline & Frequency & Percent \\
\hline Good attitude & 209 & $76.3 \%$ \\
\hline Poor attitude & 62 & $23.7 \%$ \\
\hline Total & 271 & $100 \%$ \\
\hline
\end{tabular}

\section{Comparison of attitude towards VCT across independent variables}

Comparing attitude towards VCT to different demographic characteristics (age, marital status, educational status............) using the chi-square test indicated that there was statistically association between attitude towards VCT and the respondents' educational status ( $p=0.010)$, as well as between attitude towards VCT and occupation $(p=0.021)$, There was no association between attitude towards VCT and the other 1ndipendent variables.

\section{Intention and practice of voluntary counselling and testing (VCT)}

Out of 271 study participants, $96(35.0 \%)$ did not undergo HIV test, while the remaining $175(65 \%)$ were tested. Among study subjects who were not tested for HIV, 96 (35\%) had future intention of having VCT and 147 (53.6 \%) of them reported that they can decide by themselves to undertake VCT, while the remaining 121 (46.4\%) they can't decide by themselves to undertake VCT. Among study participants who were tested, $52(19.0 \%)$ were tested before marriage, $90(32.8 \%)$ during pregnancy and $33(12.0 \%)$ were tested during delivery.

\section{Comparison of practice towards VCT across independent variables}

Comparing practice towards VCT to different demographic characteristics (age, marital status the chi-square test indicated that there was statistically association between practice towards VCT and the respondents' religion $(p=0.019)$, as well as between practice towards VCT and monthly income $(\mathrm{p}=0.041)$,

There was no association between practice towards VCT and the other independent variables

Practice of VCT out of 271 study participants 200 (73.0\%) had good practice towards VCT, while the remaining $71(27.0 \%)$ had a poor practice.

\section{INTENTION AND PRACTICES OF BREAST FEEDING}

Almost all of the mothers in the study area (88.7\%) ever breastfed, of which one half initiated breast feeding in the first hour of delivery. In addition, around $10.2 \%$ of the mothers gave either butter or water to their new born before initiation of breast feeding. Out of 241 children less than six months old only $1(0.36 \%)$ was not exclusively on breastfed while $240(88.5 \%)$ were exclusively breastfed. The majority of mothers who gave mixed food such as porridge, cow milk, formula milk and adult food for their children started before four months, whereas, adult food was started after four months. Mothers already provide some types of food and fluid like water while not considering them as food. They were asked when they intend to start additional (supplementary) food, and 1 ( 0.4 $\%$ ) want to start before six months, 86 (31.4\%) six to twelve months, and $122(44.6 \%)$ after one year.

Mother reported faced problems in relation to breast feeding were breast engorgement $19(6.9 \%)$ and infants' cries' or unhappy $15(5.5 \%)$, and no food or milk to feed the infant $16(8.8 \%)$. The other practice that the study revealed was wet nursing 10 $(3.6 \%)$. The reason of the respondents for wet nursing were separation of the mother from the child $2(0.7 \%)$, breast of the mother had no enough milk $2(0.3 \%)$ and due to sickness of the mother $7(2.6 \%)$.

As reported by respondents those who breast fed their child were their sisters $6(2.2 \%)$. In case of the assessment of respondents' knowledge on infant feeding options for HIV positive mother, common responses were not feeding breast at all 95 (34/7 
$\%)$, give formula feeding 80 (39.2\%), cow milk 43 (15.7\%), mixed food $26(9.5 \%)$, and $27(9.9 \%)$ of them did not know any feeding options.

\section{Discussion ANd CONCLUSION}

This study is attempted to assess the intention and practices of mothers on VCT and breast feeding practices in the context of HIVIAIDS. In this study it was found that majority of study participants had ANC follow up during the last pregnancy. This finding is in line with study done in Jimma town on pregnant and lactating mothers that the study participants had ANC check up during their last pregnancy [36]. In this study it was found that majority of the study subjects had considerably high knowledge score of HIVIAIDS and less knowledge of MTCT and PMTCT. Moreover, this finding is in harmony with other similar studies done in Hong Kong and China on women attending ANC clinic base line survey of PMTCT in Ethiopia on 6 regions other than D.U.R.H on lactating mothers and the study done in Jimma on pregnant and lactating mothers [7, 14, 36].

In this study about more than half of the respondents had good attitude towards VCT. This finding is in line with a study in Jimma town on pregnant and lactating mothers, where the majority of the respondents had good attitude towards VCT [36]. Out of tested study participants half of them were tested during the last pregnancy which is somewhat similar with that of study done in Jimma [36].

In case of preference of hearing HIV test result; participants agreed on face to face, parents, enclosed in envelop, and the least agreement being by relatives in that order. In case of communication of positive HIV test result communication, majority of study participants agreed to communicate with their partners; and the rest agreed to communicate with their family members (children, brother, sister) that similar with a study done in Lusaka, Karatina, and Homa Bay in Kassena Nankana district of North Ghana and China showed that pregnant mothers shared their HIV test result with someone (partner, family member, friend) particularly in Kenya and Karatina, Lusaka more than half of women shared their HIV test result with their partner [15-17, 21, 31].

Regarding breast feeding practices and initiation of mothers on duration of breastfeeding and starting additional/ supplementary foods; this study revealed that almost all mothers of the study participants initiate breast feeding with in the first hour of delivery.

In this study exclusive breastfeeding practice is very high. unlike similar study done in Lusaka that mixed feeding were given at three months of age, study done in Ethiopia, that weaning was started before the age of four months and a study done in Jimma town where mixed feeding is a common practice before six months of age $[21,33,36]$ even if deferent results conducted in the world and different part of the country suggest that there is rare practice of exclusive breast feeding, our result predict that exclusive breast feeding practice is high in the area. This could be due to knowledge and attitude of the mothers towards breast feeding practice plus that might be in result of occupational status of the mother.

Furthermore this study assessed the intention of mothers on duration of breast Feeding. As such the majority of them want to breastfeed for 6 to 12 months and for 13 to 18 months. This finding was similar with studies done in Butajira, Ethiopia and Durban, South Africa and $[23,33]$

The findings from this study in relation to prevention of HIV transmission revealed that mothers had good knowledge of HIVIAIDS and on MTCT and PMTCT. There was statistically association between knowledge and the respondents' educational status $(p=0.037)$. The study participants also have good attitude towards VCT which may have a contribution to intention of the mothers to have HIV test. There was statistically association between attitude towards VCT and the respondents' educational status $(p=0.010)$, as well as between attitude towards VCT and occupation ( $p=0.021)$, Majority of the study participants who didn't undergo HIV test reported an intention to have HIV test. However in actual practice more than two -fourth of the study participants reported to had had HIV test. This implies that the intention to have HIV test and the practice of undergoing HIV test were comparable. There was statistically association between practice towards VCT and the respondents' religion $(p=0.019)$, as well as between practice towards VCT and monthly income $(p=0.041)$.

Majority of the mothers in this study know the availability of VCT service but the Majority don't know the availability of infant feeding counselling in a nearby health Facility. Majority of the mothers also responded that they have the accessibility to these services. Exclusive breast feeding is relatively high. As such the majority of them want to breastfeed for 6 to 12 months and for 13 to 18 months.

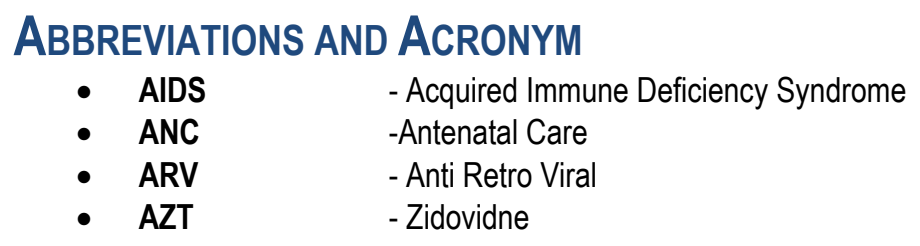




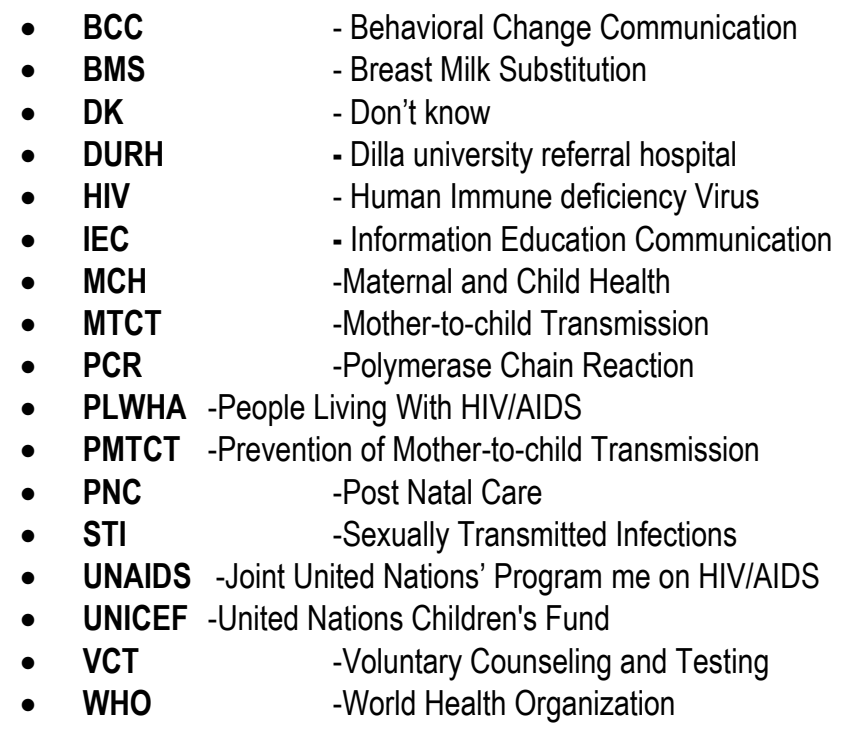

\section{ACKNOWLEDGMENT}

I would like to express my gratitude to data collectors and community of dilla for their unreserved help and facilitation.

My heartfelt thanks also goes to Rift Valley University Hawassa Campus for giving me this chance for practicing this Research work. Finally, I am greatly indebted to my Wife Netsanet Desalegne who gave me courage deserves my utmost gratitude for helping me to do this Research work

Conflict of Interest: None declared.

Source of Funding: No source of funding.

\section{REFERENCES}

1. UNAIDS. (2010). Progress report on the global response to the HIVIAIDS epidemic, Switzerland, Geneva: 6-12.

2. $\mathrm{MOH}$. (2011). CDC department. AIDS reports, 5th edition, Addis Ababa, Ethiopia, 1-10, 25-26.

3. UNAIDS. (2009). Prevention of HIV transmission from mother to child: strategic options, Geneva, Switzerland, 5-10.

4. WHO. (2009). HIV transmission through breast feeding: A review of available evidence, Geneva, Switzerland, 8-18.

5. Wondwossen. (2011). Amogne Prevention of mother to child HIV transmission (MTCT). Proceeding of the 15th annual conference of the EPHA, Addis Ababa, Ethiopia, 59-63.

6. USAID. (2001). Support for Analysis and Research in Africa (SARA). Prevention of HIV in Africa: Practical guidance for programme, 2001, Washington DC, USA, 1-20.

7. Deneke, K., Rubin, J., Franklin, N., \& Guyon, A. (2011). Preventionof mother to child transmission (PMTCT): base line survey, AddisAbaba, Ethiopia, 34-43.

8. Dabis, F., Newell, M. L., Fransen, L., Saba, J., Lepage, P., Leroy, V., ... \& Nduati, R. (2000). Prevention of mother-to-child transmission of HIV in developing countries: recommendations for practice. Health policy and planning, 15(1), 34-42.

9. Max, E. (2009). AIDS in Africa, 2nd edition, Kluwer Academic, New York, 251-568.

10. Kalichman, S. C., \& Simbayi, L. C. (2003). HIV testing attitudes, AIDS stigma, and voluntary HIV counselling and testing in a black township in Cape Town, South Africa. Sexually transmitted infections, 79(6), 442-447.

11. Msellati, P., Hingst, G., Kaba, F., Viho, I., Welffens-Ekra, C., \& Dabis, F. (2001). Operational issues in preventing mother-to-child transmission of HIV-1 in Abidjan, Cote d'Ivoire, 1998-99. Bulletin of the World Health Organization, 79, 641-647.

12. UNAIDS. (2011). Counselling and voluntary HIV testing for pregnant women in high HIV prevalence countries: Elements and issues, Geneva, Switzerland, 6-14.

13. UNAID. (2009). Linkage project. Breast feeding and HIVIAIDS Frequently Asked Questions (FAQ), 2009, FAQ sheet 1, 1-5.

14. Ho, C. F. (2011). HIVIAIDS and risk behaviours in Hong Kong Chinese Pregnant women. Journal of advanced nursing, 43(3):238-245.

15. Hesketh, T., Duo, L., Li, H., \& Tomkins, A. M. (2005). Attitudes to HIV and HIV testing in high prevalence areas of China: informing the introduction of voluntary counselling and testing programmes. Sexually transmitted infections, 81(2), 108-112.

16. Bsaiden, F., Remes, P., \& Baiden, R. (2005). Voluntary counseling and HIV testing for pregnant women the kassena Nankana disrict of North Ghana. AIDS Care, 17(5), 648-657.

17. USAIDS, Horizons. (2010). Empowering communities to respond to HIVIAIDS. Linkage project academy, Lusaka, Zambia, 1626. 
18. ICRW. (2012). Community involvement and the prevention of mother to child transmission of HIVIAIDS, Washington DC, USA, 1-6.

19. Suryavanshi, N., Jonnalagadda, S., Erande, A. S., Sastry, J., Pisal, H., Bharucha, K. E., ... \& Shankar, A. V. (2003). Infant feeding practices of HIV-positive mothers in India. The Journal of nutrition, 133(5), 1326-1331.

20. England, L., Brenner, R., Bhaskar, B., Simons-Morton, B., Das, A., Revenis, M., ... \& Clemens, J. (2003). Breastfeeding practices in a cohort of inner-city women: the role of contraindications. BMC Public Health, 3(1), 28.

21. Omari, A. A., Luo, C., Kankasa, C., Bhat, G. J., \& Bunn, J. (2003). Infant-feeding practices of mothers of known HIV status in Lusaka, Zambia. Health policy and planning, 18(2), 156-162.

22. USAID. (2009). Counselling mothers on infant feeding for the prevention of mother to Child transmission of HIV: A job aid for primary health workers, 1-17.

23. Seidel, G., Sewpaul, V., \& Dano, B. (2000). Experiences of breastfeeding and vulnerability among a group of HIV-positive women in Durban, South Africa. Health policy and Planning, 15(1), 24-33.

24. WHO. (2011). Are WHO/UNICEF/UNAIDS recommended replacement milks for infant of HIV infected mothers appropriate in South African context, 82(3):164-169

25. MOH. (2011). Disease prevention and control department HIVIAIDS and other STDs prevention and control team. National guideline on the prevention of mother to-child transmission of HIV in Ethiopia, Addis Ababa, Ethiopia, 6-31.

26. MOH. (2010). Disease prevention and control department HIVIAIDS and other STDs Prevention and control team. Accelerating access to HIVIAIDS treatment in Ethiopia, Road map for 2008-2010, Addis Ababa, Ethiopia, 7-9.

27. MOH. (2009). Disease prevention and control department HIVIAIDS and other STDs prevention and control team. National guidelines for voluntary HIV counseling and testing in Ethiopia, Addis Ababa, Ethiopia, 9-16

28. Linkages. (2010). Infant feeding options in the context of HIV, Academy for Educational Development, Washington, DC 20009. 3-17.

29. UNIDS. (2010). HIV and Infant feedings: A guide for health care managers and supervisor, Switzerland, Geneva, 24-58.

30. Goldani, M. Z., Giugliani, E. R. J., Scanlon, T., Rosa, H., Castilhos, K., Feldens, L., \& Tomkins, A. (2003). Voluntary HIV counseling and testing during prenatal care in Brazil. Revista de Saúde Pública, 37(5), 552-558.

31. Rutenberg, N. (2009). HIV Voluntary Counselling and Testing: An Essential Component in Preventing Mother-to Child Transmission of HIV; Horizons Research Summary. Washington, D.C.: Population Council.

32. Gebriel, A. W. (2000). Determinants of weaning practices. Ethiopian Journal of health development, 14(2), 183-189.

33. Bekele, A., \& Berhane, Y. (1998). Weaning in Butajira, south Ethiopia: a study on mothers' knowledge and practice. Ethiopian medical journal, 36(1), 37-45.

34. Abate, G., Kogi-Makau, W., \& Muroki, N. M. (1999). Child-feeding practices as predictors of nutritional status of children in a slum area in Addis Ababa, Ethiopia. Ethiopian Journal of Health Development, 13(3), 229-238.

35. Rutenberg, N. (2003). Infant feeding counseling within Kenyan and Zambian PMTCT services: How well does it promote good feeding practices?.

36. Cherinet, H. (2008). Assessment of Knowledge, attitude and practice among mothers About VCT and feeding of infants born to HIV positive women in Jimma town, 2740 (Masters thus is submitted to community Health Department). 